\title{
O uso do Smartphone em sala de aula na disciplina de História: desafios e possibilidades
}

\section{Use of Smartphone in classroom in the discipline of History: challenges and possibilities}

\author{
ELEANDRO VIANA DA ROSA \\ Universidade Federal do Rio Grande do Sul (UFRGS) \\ FELIPE BECKER NUNES
}

Antonio Meneghetti Faculdade (AMF)

Resumo: Este trabalho buscou compreender o papel do professor de História em meio às TICs, tendo como enfoque o uso do smartphone no ambiente escolar. A metodologia utilizada foi qualitativa e descritiva, tendo por referência bibliografia relativa ao tema e questionários aplicados com professores de História dos anos finais do ensino fundamental. Como resultado observou-se o interesse da maioria dos professores em receber formação; a necessidade de maior oferta, por parte governo, de cursos para esta finalidade e o potencial que a aprendizagem móvel traz para professores e educandos.

Palavras-chave: Smartphone. Ensino de História. Prática Docente.

\begin{abstract}
This work sought to understand the role of History teachers in the midst of ICTs, focusing on the use of smartphones in the school environment. The methodology adopted was qualitative and descriptive, with reference to bibliography related to the subject and questionnaires applied with teachers of History of the final years of elementary school. As a result, it was observed the interest of the majority of the teachers in receiving training; the need for greater government provision to offer courses for this purpose and the potential that mobile learning brings to teachers and learners.
\end{abstract}

Keywords: Smartphone. History. Teacher Practice. 


\section{Introdução}

Na segunda metade do século XX, o Computador e as Tecnologias da Informação e Comunicação (TICs) trouxeram novas formas de concepção de tempo e espaço. "O distanciamento espacial não mais implicava o distanciamento temporal, assim permitindo ao indivíduo experimentar eventos simultâneos, apesar de acontecerem em lugares completamente distintos" (VALENTIM, 2018; THOMPSON, 2002). Essas transformações impactaram a sociedade e a educação, muito embora essa última não tenha acompanhado tais mudanças com o mesmo ritmo.

Também, o papel do professor em sala de aula foi transformado, ocorrendo a mudança de postura de agir como um detentor de verdades, e passar a ser considerado mediador no processo ensino-aprendizagem, sendo ele ao mesmo tempo agente e ator neste ensino, já que o conhecimento, em constante construção, não é alcançado na sua totalidade. Entretanto, essa mudança de concepções sobre o papel do professor em sala de aula não implica a sua dispensa, tendo em vista que, conforme aponta Pinsky (2015, p. 20 - 22), "ele é o responsável por articular o patrimônio cultural ao universo do aluno, bem com organizar a informação transmitida pela mídia em conhecimento".

O uso das TICs em sala de aula ainda hoje é objeto de controvérsias. De um lado, um grupo de professores e especialistas com publicações em revistas especializadas, sites e matérias que mostram o potencial aberto pela internet e pelas TICs e, de outro, receio de alguns professores, carência na oferta de uma formação continuada para os mesmos, dificuldade de acesso à internet de banda larga, leis "caducas", como a Lei Estadual (RS) n 12.884 de 04 janeiro de 2008, que proíbe o uso do smartphone em sala de aula, e a própria dificuldade dos educandos em ver nas tecnologias, para além do lazer e da descontração, uma possibilidade crítica para o uso educacional, conforme apontou Valentim (2012) em pesquisa em escola da rede municipal do estado da Paraíba.

No contexto escolar, o aluno, atualmente, dispõe ou pelo menos deveria dispor de novas tecnologias que possam servir de base para pesquisas dentro e fora da sala de aula. A internet possibilitar ter acesso a inúmeros sites, blogs, canais de vídeo como o YouTube com temáticas específicas relacionadas à História.

Este novo contexto educacional, rico em possibilidades, traz consigo novos desafios ao professor, como a confiabilidade das informações juntamente com a apropriação e questionamento dos alunos, o que requer como resposta uma formação continuada, seja no âmbito da epistemologia da disciplina ou seja nas TICs. Para atender às novas demandas é necessário, portanto, conjugar no ensino, o conhecimento disciplinar com a aplicação das TICs, principalmente com o uso dos smartphones na educação para o ensino-aprendizagem, cuja é a denominação dada à mobile learning.

A mobile learning, nas palavras de Formiga (2017, p. 36) é "particularmente importante para o ensino de História, pois tal disciplina é comumente entendida como antiquada e sem relação com o presente". Ela traz consigo "o aprimoramento das habilidades cognitivas e o interesse frequente e crescente pelo conhecimento" (FORMIGA, 2017, p. 36). 
Na mesma linha de pensamento, Vieira e Ferreira (2016, p. 209) "chamam a atenção para a capacidade potencializadora que a mobile learning guarda, se pensada e executada em termos didáticos, tendo em vista a aprendizagem e o desenvolvimento de uma consciência histórica dentro e fora da sala de aula". Se pensarmos a sala de aula, precisamos levar em consideração a estrutura do ambiente escolar. Para ambos os casos (dentro e fora de sala de aula), o nível de conhecimento tanto do professor quanto dos alunos, deve ser levado em consideração antes de planejar e utilizar alguma TIC com este propósito.

A partir do que foi exposto, este artigo analisa a problemática do uso do smartphone nas aulas de História no processo de ensino-aprendizagem, em seus limites e possibilidades, por meio da mobile learning. Para alcançar tal objetivo foram aplicados questionários semiestruturados destinados a professores de História em atividade, seguidos de análise qualitativa e interconectada à bibliografia.

\section{Trabalhos Relacionados}

Nesta subseção serão elencadas algumas possibilidades para (re)pensar a prática pedagógica dentro e fora da sala de aula, sendo tomado por base alguns trabalhos publicados. Foram selecionados os trabalhos de Paiva (2017); Satiko Fukuzaki (2010) e Vieira e Ferreira (2016) por se assemelhar à temática da pesquisa conduzida neste artigo.

Paiva (2017) realizou um trabalho, por meio da metodologia WebQuest, com a turma do $3^{\circ}$ Ano do Curso Técnico Integrado ao Ensino Médio do Instituto Federal de Educação, Ciência e Tecnologia do Acre (IFAC). A metodologia teve por base a reduzida carga horária de 45 horas por ano para lecionar História. O tema escolhido foi "Sócrates e seu legado". A atividade foi realizada da seguinte maneira: "dois grupos de 4 alunos com a temática Grécia Antiga (denominados grupo 1 e 2) e dois grupos de 3 alunos com a temática Jogos Olímpicos (denominados 3 e 4)." O trabalho foi realizado com sites e em grupos, os grupos foram avaliados levando-se em consideração diversos fatores como domínio do conteúdo, organização, linguagem e domínio do tempo.

Satiko Fukuzaki (2010) trouxe um modelo de WebQuest tendo em vista um Projeto de Intervenção Pedagógica na Escola. O tema apresentado foi a Ditadura Civil-Militar a qual poderia ser aplicada com os alunos do $9^{\circ}$ Ano. Oficinas foram sugeridas, infelizmente não é possível refletir sobre os resultados obtidos, pois trata-se de uma sugestão pedagógica, no entanto, por ser uma prática que envolve a internet, acredita-se que na prática exista um grande envolvimento por parte dos alunos.

Possibilidades de trabalho envolvendo o uso do smartphone não estão restritas à sala de aula, um exemplo desta aplicabilidade está presente no artigo "As aplicações móveis no ensino de História e no desenvolvimento da consciência histórica" de autoria de Helena I. A. Vieira e Cristiano. A. F. Ferreira. O artigo explora a mobile learning por meio de dois aplicativos "Vês Tudo" e "O Porto na Nuvem".

Vieira e Ferreira (2016) utilizaram aplicativos "com o objetivo de explorar o patrimônio local de uma forma diferente da tradicional, despertando o interesse, a motivação dos alunos em observar a herança que os rodeia" (VIEIRA; FERREIRA, 2016, p. 210). Os autores consideraram 
de forma geral que a familiaridade com o uso das tecnologias por parte dos alunos trazem consigo um potencial motivador para a curiosidade, e, "para o desenvolvimento de uma consciência histórica na medida em que fornecem acesso a um vasto conjunto de informações, previamente selecionadas pelo professor ou não, que depois pode ser alvo de análise crítica por parte dos alunos" (IBIDEM, 2016, p. 2018), além disso, dinamizam as visitas de estudo e retiram a ideia de que se trata de um simples passeio nas saídas de campo.

Os trabalhos mostram as potencialidades que o uso do smartphone e a mobile learning guardam, o que desmistifica a ideia de que só servem para distrair ou de que os alunos são incapazes de utilizar bem estes recursos. Os trabalhos trazem subsídios para pensar como utilizar o smartphone enquanto recurso tecnológico. Esta pesquisa tem por diferencial a reflexão do uso da mobile learning dentro e fora do ambiente escolar, a formação do professor, suas opiniões, ações e a preocupação em localizar as principais dificuldades na prática pedagógica no contexto do ensino de História.

\section{Prática Docente e Ensino de História}

É necessário, primeiramente, pensarmos a formação docente - em cursos de formação inicial e continuada - voltada para o uso das tecnologias. Historicamente, o governo buscou estabelecer algumas iniciativas para tentar dar conta do novo desafio imposto à educação. Em 1997, por meio da Portaria no 522/MEC surge o Programa Nacional de Tecnologia Educacional (ProInfo) para levar às escolas computadores, recursos digitais e conteúdos educacionais (MEC, 2019). Em 2006, foi a vez da Universidade Aberta do Brasil (UAB), plataforma "com a finalidade de expandir e interiorizar a oferta de cursos e programas de educação superior no País" (CAPES, 2019) e, em 2016, desponta o programa Hora do ENEM (Exame Nacional do Ensino Médio) que, embora direcionado a alunos concluintes do ensino do médio, permite ao professor, por meio das vídeo aulas de outros professores, repensar algumas estratégias didáticas.

Estas iniciativas, embora louváveis, diga-se de passagem, ainda são insuficientes. Prova disso são os dados da CETIC Educação 2016 (CETIC, 2016), os quais mostram que, 91 \% dos professores ainda aprendem sozinhos a utilizar a internet juntamente com o computador. Ou seja, o desafio persiste. A formação continuada e o domínio dos instrumentos que a internet traz consigo são fundamentais, pois possibilitam ao professor as condições de mediar o conhecimento.

Os Parâmetros Curriculares Nacionais (PCNs) - Terceiro e Quarto Ciclos do Ensino Fundamental História entram em consonância com o que foi dito, uma vez que um de seus objetivos é justamente "saber utilizar diferentes fontes de informação e recursos tecnológicos para adquirir e construir conhecimentos".

Freire e Rodrigues Junior (2010) salientam que "a introdução das novas tecnologias na educação não pode ser vista como panaceia, e sim como forma de possibilitar melhorias, desde que sejam integradas ao ensino de forma pertinente" (FREIRE; RODRIGUES JUNIOR, 2010). De forma análoga, Schmidit (2015) enfatiza que "um dos grandes desafios dos professores foi e continua sendo superar o ensino tradicional, tema de encontros, seminários, congressos 
educacionais, entre outros". Preocupada com a problemática do ensino tradicional e com o aprendizado do aluno, a autora evidencia o papel do professor nesta transformação.

O professor de História pode ensinar o aluno a adquirir as ferramentas de trabalho necessárias; o saber-fazer, o saber-fazer-bem, lançar os germes do histórico. Ele é o responsável por ensinar o aluno a captar e a valorizar a diversidade dos pontos de vista. "Ao professor cabe ensinar o aluno a levantar problemas e a reintegrá-los num conjunto mais vasto de outros problemas em problemáticas" (SCHMIDT, 2015, p. 57). Portanto, estes aspectos devem ser levados em consideração nas práticas que envolvam a mobile learning, que será abordada de forma mais detalhada na próxima subseção.

\section{Ensino de História no contexto da mobile learning}

Apesar da importância do uso pedagógico dos recursos tecnológicos e das iniciativas pelo governo federal, em âmbito estadual tem-se a Lei n 12.884 de 3 de janeiro de 2008 que, em seu Art. $1^{\circ}$ deixa claro que "fica proibida a utilização de aparelhos de telefonia celular dentro das salas de aula, nos estabelecimentos de ensino do Estado do Rio Grande do Sul". Esta restrição também pode ser encontrada na legislação de vários outros municípios gaúchos, inclusive Porto Alegre, capital gaúcha, que pela Lei n. 11.067 de 10 de maio de 2011 - dispõe para a proibição do uso dos aparelhos celulares em sala de aula.

A legislação, portanto, não leva em consideração possibilidades pedagógicas do uso do smartphone, já que a mesma não é mencionada, é contraditória diante das iniciativas do governo federal, e caduca, se levarmos em consideração que já se passaram dez anos e de lá pra cá muita coisa mudou.

Ainda sobre o uso do smartphone, quando utilizado em práticas pedagógicas, cabe ao professor o devido cuidado com os direitos autorais e o dever de orientar seus alunos sobre a importância do respeito para com os mesmos. Embora esta não seja a temática deste trabalho, convém esclarecer ao leitor sobre a importância e o que são os direitos autorais.

Blattmann e Rados (2001) apontam que "é fundamental que seja reconhecida a importância do trabalho do intelectual e defender interesses, sejam eles profissionais, sociais, culturais ou pessoais" (BLATTMANN; RADOS, 2001, p. 87). Martins Filho (1998) completa e esclarece a abrangência dos direitos autorais, ao dizer que "O importante a ressaltar é que todas as obras intelectuais (livros, vídeos, filmes, fotos, obras de artes plásticas, música, intérpretes etc.), mesmo quando digitalizadas, não perdem sua proteção, portanto não podem ser utilizadas sem prévia autorização." (MARTINS FILHO, 1998, p. 187).

No que concerne às inovações tecnológicas nota-se que "apesar do crescente aumento da informação e dos meios de difundi-la e administrá-la, ocorre paralelamente um aumento da distância entre os que sabem articulá-las, pensa-las e refleti-las" (SCHMIDT, 2015, p. 63). Diante do desconhecimento e da dificuldade de alguns educadores em aceitar o uso das TICs, a autora alerta que "quando acolhidas pelos educadores, tais inovações tecnológicas têm normalmente sido usadas como técnicas de ensino, estratégias para preencher ausências de professores ou como recursos para tornar as aulas menos enfadonhas" (IBIDEM, 2015, p. 64). 
Desta forma fica evidente a necessidade de formação continuada aliando o viés epistemológico com o teórico. Giovanni e Hahn (2017, p. 157) destacam o mesmo, para eles é fundamental que a escola incorpore os recursos tecnológicos nas práticas pedagógicas, pois convém a "criação de um espaço de aprendizagem que possibilite a formação qualificada mais próxima do dia a dia dos alunos".

\section{Metodologia}

A pesquisa em questão é de caráter qualitativo, quanto à abordagem, pois preocupa-se com aspectos das dinâmicas sociais. De acordo com Gerhardt e Silveira (2009), a pesquisa qualitativa contém as seguintes características: objetivação do fenômeno; hierarquização das ações de descrever, compreender, explicar, precisão das relações entre o global e o local em detrimento do fenômeno, observâncias das diferenças entre o mundo social e o mundo natural; respeito ao caráter interativo entre os objetivos buscados pelos investigadores, suas orientações teóricas e seus dados empíricos, busca de resultados os mais fidedignos possíveis; oposição ao pressuposto que defende um modelo único de pesquisa para todas as ciências (GERHARDT; SILVEIRA, 2009, p. 32).

Quanto à natureza tem como característica a busca de aplicabilidade para o problema de como utilizar pedagogicamente os smartphones em sala de aula no contexto do ensino de História. Quanto aos objetivos tem caráter exploratório visto que trabalha com questionários semiestruturados e pesquisa bibliográfica.

O uso de uma simples pesquisa bibliográfica não daria conta de responder ao problema em questão: compreender o papel do professor de História em meio as TICs, em especial o uso do smartphone em sala de aula, pelo menos não na profundidade almejada, por isso, optou-se por agregar na metodologia, questionários semiestruturados, por amostragem, com professores de História dos anos finais do ensino fundamental, de escolas de rede pública e privada, com variados tempos de experiência.

\subsection{Participantes}

Os participantes desta pesquisa foram professores de História dos anos finais do ensino fundamental, com tempo de magistério variável, sendo o intervalo composto por docentes com menos de 5 anos até mais de 15 anos de experiência (Figura 1), lecionando em escolas da rede pública estadual, municipal e rede privada (Figura 2 ). 


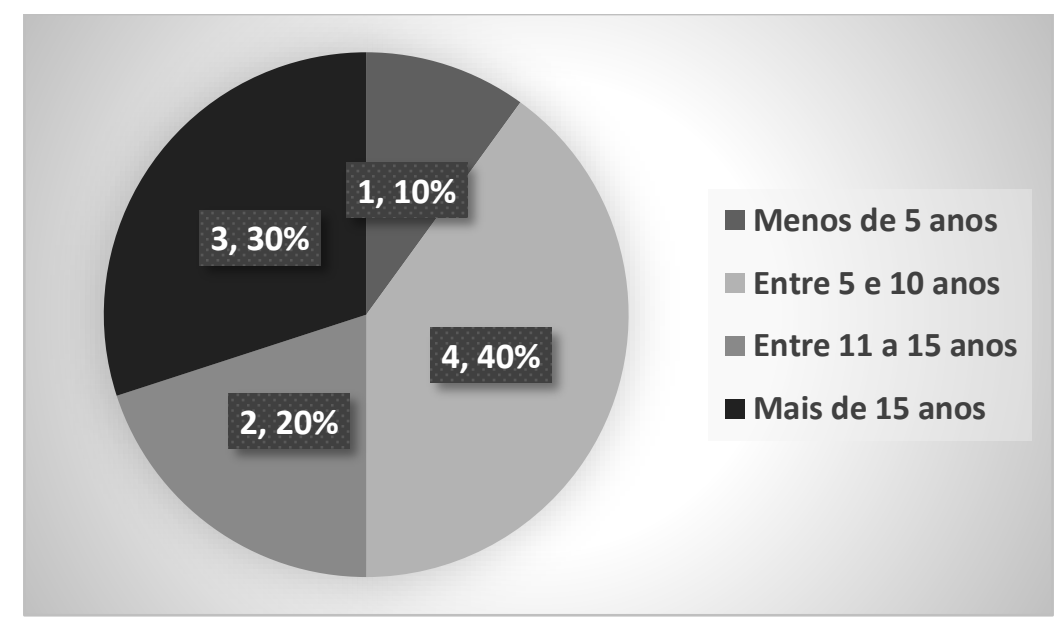

Figura 1. Tempo de Magistério

Source: The author.

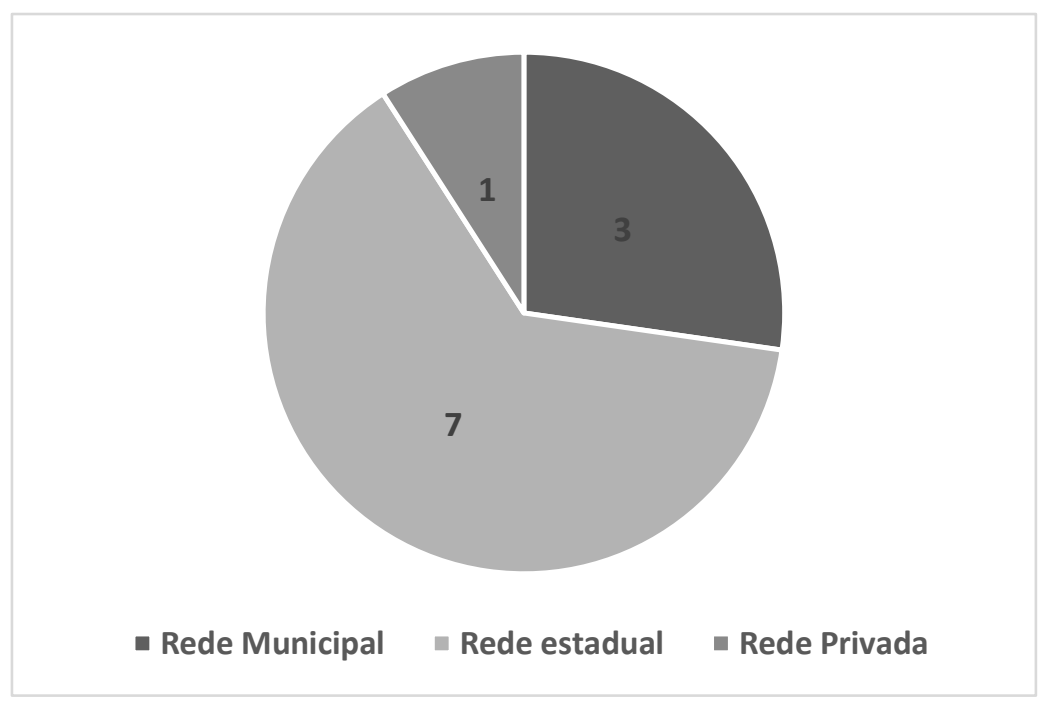

Figura 2. Âmbito de trabalho

Source: The author.

Buscando apresentar a amostragem em detalhes, esta foi composta de 10 professores, dos quais 2 trabalham na rede municipal, 6 na rede estadual, 1 na rede estadual e municipal, e 1 na rede privada. Quanto ao tempo de magistério, um professor declarou estar em início de carreira, com menos de 5 anos, 4 professores disseram ter de 5 a 10 anos de sala de aula, 2 preencheram o campo de 11 a 15 anos e 3 responderam que possuem mais de 15 anos, provavelmente no fim de carreira do magistério.

\subsection{Design do Estudo}


A pesquisa foi composta por quatro fases:

$1^{\circ}$ - Elaboração do problema de pesquisa e levantamento bibliográfico, sobre o tema. 0 levantamento bibliográfico foi feito no repositório digital LUME., plataforma SciELO, Catálogo de Teses e Dissertações da Capes, e livros e revistas da área.

$2^{\circ}$ - Elaboração do questionário semiestruturado, tendo por objetivo conhecer o professor em seu tempo de experiência, condições de trabalho e conhecimentos sobre as TICs enquanto recurso pedagógico.

$3^{\circ}$ - Aplicação dos questionários, realizada com professores das redes estadual, municipal e privada.

$4^{\circ}$ - Análise dos dados, que foi realizada primeiramente considerando as respostas dos professores, que foram agrupadas nas questões presentes no questionário para simplificar o processo de análise, em seguida as mesmas foram analisadas tanto isoladamente quanto conjuntamente, o que permitiu estabelecer um "perfil" dos entrevistados tomando por base seus posicionamentos, tempo de serviço, entre outros. Feito isto, colocou-se este "perfil" em comparação com a bibliografia disponível. Isto possibilitou a consolidação de uma análise crítica dos resultados.

\subsection{Análise e Instrumentos de Coleta de Dados}

A pesquisa de caráter qualitativa foi realizada com 10 professores que trabalham em diferentes níveis de ensino na área de História. Os dados foram coletados por meio de um questionário semiestruturado, composto por 16 questões, sendo 4 questões de múltipla escolha e 12 abertas. O objetivo do questionário foi: conhecer a realidade dos professores, tempo de sala de aula, se trabalhavam em rede pública ou privada, entre outros aspectos, para, posteriormente, aliar todas estas informações ao referencial teórico encontrado e, com isso, produzir uma reflexão que, combinando a teoria com a prática, encontrasse alternativas para o uso eficaz do smartphone em sala de aula para o ensino de História.

Os posicionamentos dos professores também foram analisados no que concerne à lei 12.884 de janeiro de 2008, que proíbe o uso de aparelhos de telefonia em sala de aula. Investigou-se a existência ou não oportunidades de uma formação continuada e se estas se deram por iniciativas do próprio governo ou por meio de recursos próprios e, ainda, se os docentes estariam interessados em receber tal formação caso Ihes fosse oferecida.

\section{Resultados e Discussões}

Esta seção tratará da análise dos resultados obtidos em pesquisa qualitativa realizada com um total de 10 professores de História dos anos finais do ensino fundamental, de distintas realidades educacionais, tempo de docência, variadas concepções pedagógicas relacionadas ao uso do smartphone em sala de aula, suas principais dificuldades no trato com este tipo de tecnologia, seu posicionamento frente à Lei Estadual n. 12.884 de janeiro de 2008, que proíbe o uso de aparelhos de telefonia em sala de aula, sua formação e o interesse em obtê-la. 
Sobre a atuação profissional, a maioria dos docentes que responderam ao questionário (6), disse trabalhar somente em rede estadual. Por conta disso, muitas das respostas possibilita compreender e indagar a realidade da educação pública frente às TICs. Houve somente um professor que lecionava em escolas pertencentes a redes diferentes. Segundo este professor, há diferenças frente às possibilidades do uso das TICs quando se compara escola pública e privada. Em alusão a escola pública citou o seguinte:
"Sim, as escolas possuem equipamentos, mas em quantidade insuficiente, ou seja, não é possível o uso de todos os equipamentos por todos os alunos ao mesmo tempo. Analiso também o acesso à internet nos laboratórios, sendo precários nas redes estaduais." (PROFESSOR "L1").

Após as três perguntas iniciais sobre o local de trabalho e tempo de magistério, a quarta questão abordou sobre a Lei Estadual 12.884, que proíbe o uso de aparelhos de telefonia em sala de aula, as respostas foram diversas. A maioria ( 8 professores) disse que o celular pode ser utilizado em sala de aula para fins pedagógicos, desde que com a mediação ou supervisão. 0 professor "M", por exemplo, argumenta que:

"o celular é um objeto que faz parte do cotidiano dos alunos e que a luta contra seu uso é uma luta perdida. O que resta é problematizar seu uso de forma a encontrar um objetivo pedagógico para o mesmo".

Discordando dos demais colegas, a professora "L" diz que:

"(...) alunos mal-intencionados poderão usar imagens
captadas em aula para nos prejudicar (editando e
produzindo fake news)".

O professor "J" também é contra, mas justifica afirmando que, na rede estadual os alunos não utilizam de forma adequada, além disso, o sinal de WiFi é de péssima qualidade em boa partes das escolas que ele frequenta. Rehfeld (2017) em seu trabalho de conclusão de curso intitulado "Utilização de ferramentas digitais para o ensino de História" defende o uso das diversas tecnologias na aula de História. Apoiada em Kenski (2012, P. 45), defende que as TICs "quando bem utilizadas provocam a alteração dos comportamentos dos professores e alunos, levando-os ao melhor conhecimento e maior aprofundamento do conteúdo estudado". Ainda que não faça menção direta às fake news, a autora destaca a mediação do professor nas pesquisas da internet para que o aluno tenha referenciais sérios.

Imerso na realidade digital, o professor de História necessita, mais do que nunca constantemente formação. É papel não só do professor, mas também do próprio governo fornecer capacitação para que todos possam ter uma formação adequada e os alunos, por conseguinte, uma educação de qualidade. Por conta disso foi questionado na quinta e sexta pergunta se os professores já receberam algum curso de formação continuada relacionado às mídias e qual a 
contribuição destas para sua formação. Como resposta 7 professores disseram que já receberam alguma formação e 3 disseram nunca ter recebido nenhuma formação.

A partir das informações fornecidas pelos professores fica evidente que, nos últimos anos, houve uma maior preocupação do governo em vincular a prática docente às TICs. Certamente insuficientes, já que as tecnologias estão em constante renovação, mas são iniciativas que precisam ser aproveitadas pelo professor e valorizadas pela comunidade.

Em meio a tantas propostas de formação docente, e o crescimento da oferta de cursos em formato EAD está aí para mostrar, torna-se necessário ter em mente que tecnologia não é sinônimo de viabilidade e pertinência, conforme salienta Fraiha-Martins e Gonçalves (2018). Tal reflexão esteve presente nos apontamentos trazidos pelos docentes. Dois professores salientaram que estes cursos ainda estão longe da realidade da sala de aula, pois "as escolas não possuem equipamentos nem condições adequadas de utilização". Entretanto, de forma geral, os professores viram contribuições positivas nestes cursos dando destaque a produção de vídeos, áudios e aulas mais dinâmicas e criativas. A este respeito, merece destaque a fala da professora "L2":

\footnotetext{
"São infinitas contribuições, as tecnologias digitais são um excelente difusor de conhecimento, dada a rapidez e ao grande conteúdo que abarca. Estamos longe do ideal. Infelizmente ainda é visto como não aula estar diante de uma televisão, computador ou celular. Temos muito arraigado em nossa cultura a ideia que aula boa é o professor falando e o aluno escutando e escrevendo" (PROFESSOR L2).
}

Ainda sobre a formação continuada, na sétima pergunta foi questionado se fizeram cursos com recursos próprios envolvendo o uso de mídias para práticas pedagógicas, sendo que dos 10 entrevistados, apenas 2 já realizaram tal investimento. Talvez isso se deva, em grande medida, por conta da escassez de recursos financeiros tendo em vista que a maioria dos professores entrevistados são da rede estadual, onde o salário é menor, principalmente se comparado com o que outros profissionais recebem na maioria dos municípios.

Sabendo-se que grande parte dos professores entrevistados já receberam alguma formação relacionada às mídias (por parte do governo), conforme exposto anteriormente e que dois o fizeram com recursos próprios, procurou-se explorar na oitava questão como a formação continuada vem impactando a vida dos professores? E na nona questão foi perguntado se estão fazendo alguma prática pedagógica envolvendo o uso das mídias. Dos respondentes apenas dois nunca fizeram nenhuma prática envolvendo mídias. Entre os que responderam afirmativamente, as respostas mais comuns foram: Datashow (Projetor Multimídia), produção de vídeos para clipes e filmes de curta metragem envolvendo o uso do smartphone e uso de notebooks para a edição de filmes.

Esta nova gama de recursos pode proporcionar aulas diferenciadas, mas não podem ser vistas como um fim em si, mas como um meio para se alcançar os objetivos da aprendizagem esperados. Karnal (2010) defende que o professor sempre tem muito a oferecer na ausência de tais tecnologias. De modo semelhante o quadro negro e os livros não devem ser subestimados, pois também guardam em si o potencial para o aprendizado. 
Como o objetivo geral deste trabalho é investigar quais práticas pedagógicas são feitas envolvendo o uso do smartphone, no ambiente escolar, especificamente nas aulas de História, estabeleceu-se uma sequência de questionamentos visando não só a compreender isto como também a realidade educacional na qual estavam inseridos.

A décima questão versava sobre a frequência do uso do smartphone em sala de aula pelos alunos. Neste sentido, 7 responderam "às vezes", 2 "sempre" e 1 "nunca". O que remete a importância do planejamento de atividades pedagógicas vinculadas ao uso do celular em sala de aula, uma vez que isto faz parte do cotidiano dos alunos e até dos professores, portanto não motivo de não planejar algo fora desta realidade, a menos que condições financeiras, de equipamentos ou mesmo de sinal de Wifi impeçam. Trindade (2015) destaca:

(...) "hoje em dia, a capacidade que os alunos têm de aceder a qualquer informação com a rapidez de um clique ou do deslizar de um dedo, torna o uso de tecnologias móveis na escola cada vez mais uma realidade. Os estudantes do novo milênio estão de tal forma habituados a esta corrente constante de informação que estão "formatados" para pensar, também na escola, de uma forma diferente da de gerações anteriores. (TRINDADE, 2015, p. 207).

Se os alunos pensam neste "formato" é necessário que os professores pensem e falem a mesma linguagem para que haja entendimento e fluidez no momento do ensino. Pensando nisto foi questionado na décima primeira questão, qual o significado do termo mobile learning para os professores, no qual, apenas dois souberam trazer uma definição, os demais, 8 professores, não souberam responder. Apesar de 80 \% não souber responder, isto não significa necessariamente a ausência de aplicação de atividades envolvendo aprendizagem móvel, como será dito mais a frente, alguns professores já pediram que os alunos realizassem trabalhos extraclasse envolvendo pesquisa na internet, por exemplo. A respeito da aprendizagem móvel chama a atenção às considerações da professora "L2".

\begin{abstract}
"Acredito que o conhecimento não mais está restrito a escola. O aluno tendo onde buscar informações, aprendendo a aprender com esse sistema pode acrescentar mais valor na sua aprendizagem em História principalmente, pois sabendo que é uma disciplina onde um fato não acontece isolado, a riqueza de poder estar usando vários recursos que podem estar a distância, será mais interativo com essa mobilidade!" (PROFESSORA L2).
\end{abstract}

De volta ao assunto do smartphone, na décima segunda questão todos os professores foram unânimes ao afirmar que ele é uma realidade em sala de aula e que, mesmo quando proibido os alunos continuam a utilizar. A professora "L2" defende o uso do smartphone em sala de aula, porém faz a seguinte ressalva: as direções e os professores precisam estar preparados.

"Quanto às mídias, sinto que o conhecimento dos alunos se expandiu mais. Falar de um assunto e poder buscar informações através de fotos, filmes, documentários, enfim 
posso afirmar que ter a mídia permanente em sala de aula torna a aula riquíssima e prazerosa! Aconselho a todas as direções proporcionar salas equipadas com docentes preparados! Acabará a violência e com certeza alunos e professores sairão com qualidade de vida!" (PROFESSORA L2).

Se o smartphone é uma realidade presente em sala de aula é necessário, portanto, pensar sobre como os professores vêm se apropriando disto. Portanto, na décima terceira questão foi questionada quais as dificuldades que eles enfrentavam em construir e aplicar atividades pedagógicas envolvendo smartphones no contexto de ensino de História. Em resposta, os educadores destacaram o tempo de planejamento, o direcionamento dos alunos para este fim e ausência de formação para as TICs como as principais dificuldades.

A respeito da formação de professores Gonsales (2014) salienta que a política pública de formação de professores é marcada pela baixa valorização dos docentes como produtores e autores de seus materiais, metodologias e conteúdos. Existe uma forte penetração do mercado editorial e de empresas de Tecnologia da Informação (TI) com produtos educacionais comercializáveis, que acabam levando ao equívoco de criar estratégias apenas de capacitação instrucionista para manuseio de programas e software distribuídos "gratuitamente". O que se percebe nessas situações, em geral, é a mera substituição de dispositivos analógicos pelos digitais, deixando de lado, por exemplo, o trabalho com valores humanos e reflexões críticas em relação ao uso responsável das tecnologias. (GONSALES, 2014, p. 56).

O desafio posto ao professor é grande, porquanto, para além de dominar tais tecnologias, necessita promover uma formação humana e responsável. Os subsídios para isto podem ser adquiridos em leituras, discussão em grupos de pesquisas, participação em congressos e cursos de formação continuada (oferecidos ou não pelo governo).

Frente ao uso do smartphone, foram questionados na décima quarta questão quais os limites envolvidos em seu uso e quais as possibilidades na prática pedagógica? Para o primeiro questionamento houve ênfase no acesso a fontes de pouca confiabilidade e sinal de Wifi de pouca qualidade para a realização das atividades. Para o último, os professores deram destaque às pesquisas, aos documentários, as fotografias, a possibilidade de se produzir imagens, de se refletir sobre nossa sociedade, trocar ideias entre os colegas, realizar trabalhos em grupo, acessar acervos históricos disponíveis na internet, e ao crescimento gradual da autonomia do aluno.

Questionados na décima quinta questão sobre atividades envolvendo smartphone com conteúdo histórico, quatro professores disseram que não realizaram atividades envolvendo esta tecnologia. Entre as justificativas estão ausência de internet e dificuldades financeiras dos alunos para adquirirem o smartphone. Os demais professores alegaram utilizar apenas para pesquisas.

No que concerne à confiabilidade das fontes, é fundamental a mediação do professor, no trato das mesmas, junto aos alunos para que estes sejam capazes de aprender a "separar o joio do trigo" construindo gradualmente sua própria autonomia. Karnal (2015), em outras palavras, ressalta isto no processo supracitado: sem dúvida que a informação chega pela mídia, mas só se transforma em conhecimento quando devidamente organizada. E confundir informação com conhecimento tem sido um dos grandes problemas da nossa educação. Exatamente porque a 
informação chega aos borbotões, por todos os sentidos, é que se torna importante o papel do bom professor. (KARNAL, 2015, p. 22).

Ainda sobre a autonomia do aluno, foi questionado na última questão aos professores se realizam ou já realizaram algumas atividades extraclasse envolvendo smartphone ou criação de páginas. O retorno foi surpreendente, não só porque metade dos professores responderem afirmativamente, como também pela diversidade de atividades. Entre elas destacam-se: pesquisas na internet (no geral), criação de páginas de Facebook "história legal", uso do aplicativo "Somos Educação", e até mesmo a iniciativa, que ainda está em construção, de uma criação de uma sala de aula virtual dentro do curso de "Class Room". Conforme apontam Marquetti e Falkembach (2017), os professores devem usufruir tais recursos, pois fazem parte da realidade dos alunos, as TICs guardam diferentes possibilidades de prática didática e são extremamente motivadoras.

Porém, para que práticas pedagógicas inovadoras sejam aplicadas é necessário preparo por parte do professor, neste sentido 9 dos 10 professores entrevistados manifestaram interesse em conhecer algum tipo de proposta/abordagem para o uso de smartphones na prática pedagógica em disciplinas de História. Neste sentido, Marquetti e Falkembach (2017, p. 356) enfatizam a necessidade de criação de políticas públicas para este fim tendo em vista que "a atuação do professor, mesmo não sendo a única, é a grande responsável pelos resultados que se obtém na aprendizagem".

Da análise dos questionários pode-se concluir, de forma geral, que, embora existam leis que restrinjam o uso do celular em sala de aula, o que se vê é um cotidiano escolar cada vez mais marcado pelo uso desta e de outras tecnologias. Frente a isto, embora insuficientes, o governo vem promovendo algumas iniciativas com a promoção de cursos relacionados às mídias como, por exemplo, o Class Room, citado por um dos professores. O corpo docente, cada vez mais toma consciência de que as TICs vieram para ficar (ao menos esta é a tendência dos últimos anos), entretanto ainda carecem de formação para que a tecnologia não seja um fim em si mesmo.

Por fim, conclui-se que a aprendizagem móvel e as tecnologias contribuem significativamente para o amadurecimento do educando, na medida em que este tem sua autonomia e sua capacidade analítica frente às informações gradualmente ampliadas com a mediação do professor de História.

\section{Considerações Finais}

Este artigo teve como centro de investigação pensar como tem lidado pedagogicamente com a tecnologia, em especial o smartphone, o professor de História em suas aulas? Para responder a esta questão, optou-se pela utilização da pesquisa bibliográfica em sites como a Plataforma Scielo, revistas especializadas na área da informática, da educação e da História, consulta a Anais de Eventos, entre outros. Aliado a isto aplicou-se um questionário, composto por 16 questões que versavam sobre o tempo de docência, posicionamento diante da legislação que restringe o uso de smartphone em sala de aula, formação continuada e práticas pedagógicas com as TICs no geral, e com o smartphone em específico. 
A partir do cruzamento das informações constantes na bibliografia, nos questionários, na consulta ao site CTIC.BR, e na investigação das ações que o governo vem tomando nos últimos em relação à formação pedagógica para as TICs, notou-se que de 2014 e, especialmente, de 2017 para cá, novos cursos têm sido ofertados para os professores, conforme constou nas respostas dadas nos questionários.

Contudo, a tecnologia não é um fim em si mesmo, ela é um meio para se chegar aos objetivos educacionais propostos pelo professor, diante disso, novas investigações poderiam ser feitas como, por exemplo, verificar a viabilidade dos cursos que atualmente estão sendo oferecidos pelo governo, como o Class Room, citado por um dos professores, ou mesmo cursos com recursos privados.

O trabalho possibilitou compreender que o cotidiano dos alunos é cada vez mais tecnológico tendo em vista que a maioria dos professores respondeu que os alunos utilizam os smartphones sempre ou às vezes em sala de aula, contudo a escola, ainda que vá à mesma direção, vai a uma velocidade bem reduzida especialmente se considerarmos a qualidade da internet, a necessidade de atualização da tecnologia disponível como, por exemplo, os notebooks, a formação continuada dos professores e a inserção de prática didático/pedagógicas que sejam mais condizentes com o cotidiano do aluno, isto é, com recursos tecnológicos.

No que concerne à aprendizagem móvel, a pesquisa possibilitou compreender que esta tem grandes potenciais por aliar o interesse pela tecnologia com a potencialidade de uma maior autonomia e amadurecimento intelectual, possíveis com a mediação do professor. Porém, também guarda alguns riscos por conta da existência de muitas informações falsas na internet, por isso o professor precisa estar em constante atualização, ele é também aluno, neste sentido.

A pesquisa também possibilitou perceber o posicionamento dos professores de História diante dos smartphones e da Lei Estadual n. 12.884 no qual viram nas TICs a possibilidade do uso para fins pedagógicos, mas com mediação. Percebeu-se também que os professores têm interesse em formação continuada para as TICs, o que denota a consciência dos benefícios que estas trazem e dos desafios que precisam ser superados atualmente.

Apesar de que alguns professores já façam uso de práticas pedagógicas envolvendo as TICs, nota-se, talvez, o desconhecimento de outros sobre possibilidades pedagógicas envolvendo tanto as TICs no geral, e do celular, em específico, já que alguns professores, no questionário, responderam não ter feito atividades com este recurso. Por conta disso, optou-se por propor a metodologia da WebQuest como continuidade deste projeto de pesquisa.

Conforme a bibliografia encontrada sobre o tema (DODGE, 1995; PAIVA, 2017; COSTA; CARVALHO, 2006; MENDES, 2008), a metodologia WebQuest guarda em si um rico potencial didático- metodológico, pois traz uma modernização pedagógica, constrói no aluno, através da mediação do professor, a necessidade de pesquisa tendo em vista a seleção de informações, o que o conduz gradualmente a amadurecimento intelectual e a uma maior autonomia, e conforme o caso, maior capacidade de participação em atividades em grupo. Novas pesquisas envolvendo a WebQuest poderiam ser feitas no sentido de estimular professores para que apliquem esta 
proposta, para que assim seja possível verificar o grau de impacto no processo de ensinoaprendizagem.

\section{Referências}

BLATTMANN, U.; RADOS, G. J. V. Direitos autorais e internet: do conteúdo ao acesso. Rev. Online da Biblioteca Professor Joel Martins, Campinas, v. 2, n. 3, p. 86 - 96. Jun. 2001. Disponível em: https://periodicos.sbu.unicamp.br/ojs/index.php/etd/article/view/583/598 Acesso em: 04 Nov. 2018.

BRASIL. Programa Nacional de Tecnologia Educacional. Disponível em: http://portal.mec.gov.br/proinfo Acesso em: 28 Out. 2018.

CAPES, 2019. Disponível em: http://www.capes.gov.br/uab/o-que-e-uab. Acesso em: 28 Out. 2019

Catálogo de Teses e Dissertações da CAPES disponível em: http://catalogodeteses.capes.gov.br/catalogoteses/\#!// acesso em: 21 Out. 2018

CENTRO REGIONAL DE ESTUDOS PARA O DESENVOLVIMENTO DA SOCIEDADE DA INFORMAÇÃO. Disponível em: https://www.cetic.br/ Acesso em 17 Out. 2018.

CETIC, 2016. Disponível em: https://cetic.br/tics/educacao/2016/professores/D1A/. Acesso em: 28 Out. 2019

COSTA, F. A.; CARVALHO, A. A. A. WebQuests: oportunidades para alunos e professores. In: CARVALHO, A. A. A. (Org.). Actas do Encontro sobre WebQuest. Braga, Portugal:CIEd, 2006.

DODGE, B. WebQuest: uma técnica para a aprendizagem na rede internet. Disponível em: https://www.dm.ufscar.br/ jpiton/downloads/artigo webquest original 1996 ptbr.pdf Acesso em: 10 Nov. 2018.

ESTADO DO RIO GRANDE DO SUL. Lei n. 12884, de 3 de janeiro de 2008. Dispõe sobre a utilização de aparelhos de telefonia celular nos estabelecimentos de ensino do Estado do Rio Grande do Sul. Disponível em: http://www.al.rs.gov.br/filerepository/replegis/arquivos/12.884.pdf Acesso em 29 Out. 2018.

FORMIGA, D. de O. et. al. A utilização das tecnologias da informação e comunicação como recurso didático no ensino de história. Acta Científica. v. 26, n. 1, 2017.p. 35 - 46. Disponível em: https://revistas.unasp.edu.br/actacientifica/article/view/1052 Acesso em: 24 Out. 2018.

FRAIHA-MARTINS, F. F.; GONSALVES, T. V. O. Processos de letramento científico digital: uso de WebQuest na formação inicial de professores. Educação \& Linguagem, v. 25, n. 1, p. 75 - 93, Jan - Jun. 2018. Disponível em: https://www.metodista.br/revistas/revistas-ims/index.php/EL/article/view/8686 Acesso em: 17 out. 2018.

FREIRE, K. X.; RODRIGUES JUNIOR, J. F. Webquest: uma pesquisa ação de seu emprego no ensino Fundamental. IX Congresso Nacional de Educação - EDUCERE. III Encontro Sul Brasileiro de Psicopedagogia. 26 a 29 de outubro de 2009. PUCPR. p. 6309 - 6319. Disponível em: http://educere.bruc.com.br/arquivo/pdf2009/2633 1139.pdf Acesso em 05 Nov. 2018.

FUKUZAKI, C. S. Os desafios da escola pública paranaense na perspectiva do professor. Produções DidáticoPedagógicas 2014: A WebQuest no Ensino de História. 33 p.Disponívelem: http://www.diaadiaeducacao.pr.gov.br/portals/cadernospde/pdebusca/producoes pde/2014/ 2014 unioeste hist pdp claudete satiko fukuzaki.pdf Acesso em: 4 Nov. 2018.

FUNDAÇÃO CAPES. O que é o sistema UAB. Disponível em: http://www.capes.gov.br/uab/o-que-e-uab Acesso em 28 Out. 2018.

GeRHARDT, T. E.; SILVEIRA, D. T. (Orgs). Métodos de Pesquisa. Série Educação a Distânccia. Porto Alegre: UFRGS, 2009. 
GIOVANNI, A.; HAHN, F. A. Tecnologias educacionais no ensino de História: uma abordagem possível. Tempo, Espaço e Linguagem, Irati, v. 8, n. 2, p. 154 - 176, Jul - Dez. 2017. ISSN 2177 - 6644. Disponível em: http://www.revistas2.uepg.br/index.php/tel/article/view/10901 Acesso em: 17 out. 2018.

GONSALES, P. Recursos educacionais abertos, formação de professores e o desafio de educar na cultura digital. In: Comitê Gestor da Internet no Brasil - CGI.BR. Pesquisa sobre o uso das tecnologias da informação e comunicação nas escolas brasileiras. TIC 2013. São Paulo: CGI.BR, 2014. Coord. Alexandre F. B. p. 53 - 59. Disponível em: https://cetic.br/media/docs/publicacoes/2/tic-educacao-2013.pdf Acesso em: 11 Nov. 2018.

KARNAL, L. (Org). História na sala de aula: conceitos práticas e propostas. 6. Ed. São Paulo: Contexto. 2010.

KENSKI, V. M; Educação e tecnologias: O novo ritmo da informação. $8^{\circ}$ Ed. Campinas, SP: Papirus, 2012, 141 p.

LEI 12.884, 2008. Disponível em: http://www.al.rs.gov.br/filerepository/replegis/arquivos/12.884.pdf Acesso em: 29 Out. 2019.

Lei n. 11.067, 2011. Disponível em: http://www2.portoalegre.rs.gov.br/cgi-bin/nphbrs?s1 =000031676. DOCN. \&l=20\&u=/netahtml $/$ sirel $/$ simples.html\&p=1\&r=1\&f=G\&d=atos\&SECT1=TEXT Acesso em: 29 Out. 2019.

MARQUETTI, C.; FALKEMBACH, G. A. M. Uso dos computadores na educação: ferramentas de TI para auxiliar o professor em sala de aula. In: TAROUCO, L. M. R.; ABREU, C. de S. (Org.). Mídias na educação: a pedagogia e a tecnologia subjacentes. Porto Alegre: Editora Evangraff/ Criação Humana, UFRGS, 2017, p. 355 - 370.

MARTINS FILHO, P. Direitos autorais na Internet. Ciência da Informação, Brasília, v. 27, n. 2, p. 183-188, maio/ago. 1998. Disponível em: http://www.scielo.br/pdf/ci/v27n2/martins.pdf Acesso em: 04. Nov. 2018.

MEC, 2019. Disponível em: http://portal.mec.gov.br/proinfo. Acesso em: 28 Out. 2019

MENDES, M. Criando e utilizando Home Page como recurso pedagógico para o ensino de Geografia. 2008. Disponível em: http://www.diaadiaeducacao.pr.gov.br/portals/pde/arquivos/19696.pdf?PHPSESSID $=2010011508402857$. Acesso em 8 Nov. 2018.

PAIVA, U. B. WebQuest como recurso para aprender história no IFAC. Revista de Estudos e Pesquisas sobre Ensino Tecnológico (EDUCITEC). v. 3, n. 6, 2017, p. 119 - 130 . Disponível em: http://200.129.168.14:9000/educitec/index.php/teste/article/view/188 Acesso em: 04 Nov. 2018.

PINSKY, J. PINSKY; C. B. Por uma história prazerosa e consequente. In: KARNAL, L. (Org.). História na sala de aula: conceitos, práticas e propostas. São Paulo: Contexto, 2015 p. 17 - 36.

PCN, 1998. Disponível em: http://portal.mec.gov.br/seb/arquivos/pdf/pcn_5a8_historia.pdf. Acesso em: 29 Out. 2019

PREFEITURA MUNICIPAL DE PORTO ALEGRE. Lei n. 11.067, de 10 de maio de 2011. Proíbe o uso dos aparelhos de telefonia nas escolas públicas da Rede Municipal de Ensino e dá outras providências. Disponível em: http://www2.portoalegre.rs.gov.br/cgi-

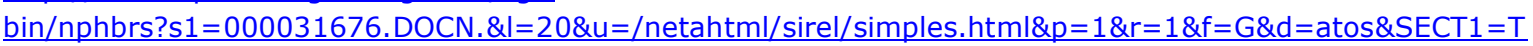
EXT Acesso em: 29 Out. 2018.

PROGRAMA HORA DO ENEM. TV Escola. Disponível em: https://tvescola.org.br/tve/serie/hora-do-enem/home Acesso em 28 Out. 2018.

REHFELD, S. R; Utilização de ferramentas digitais para o ensino de História. Trabalho de Conclusão de Curso (TCC) - Universidade Regional do Noroeste do Estado do Rio Grande do Sul (UNIJUÍ). 2017. Disponível em: http://bibliodigital.unijui.edu.br:8080/xmlui/handle/123456789/4916 Acesso em: 29 Out. 2018.

REPOSITÓRIO DIGITAL DA UNIVERSIDADE FEDERAL DO RUI GRANDE DO SUL (LUME) Disponível em: https://www.lume.ufrgs.br/ acesso em: 21 Out. 2018 
SCHMIDT, M. A. A formação do professor de História e o cotidiano da sala de aula. In: BITTENCOURT, C. (org.). O saber histórico na sala de aula. São Paulo: Contexto, 2015. $12^{\circ}$ Ed. $2^{\circ}$ Reimpressão. p. 54 - 66.

SCIENTIFIC ELETRONIC LIBRARY ONLINE. Disponível em: http://www.scielo.org/php/index.php?lang=pt Acesso em: 20 Out. 2018.

THOMPSON, J. B. A mídia e a modernidade: uma teoria social da mídia. Petrópolis, RJ: Vozes, 2002.

TRINDADE, S. M. da G. D. do C. O passado na pontados dedos: o mobile learning no ensino de história no $3^{\circ}$ CEB e no Ensino Secundário. Tese de Doutorado: Especialidade Ensino de Didática da História. Coimbra: Universidade de Coimbra. 2015.

VALENTIM, J. Cibercultura e Educação: transformações e possibilidades na prática pedagógica do ensino básico. Anais III CONAPESC, v.1, 2018, ISSN 2525-399. Disponível emhttp://editorarealize.com.br/revistas/conapesc/trabalhos/TRABALHO EV107 MD1 SA12 ID110 0704201 8193831.pdf Acesso: em 13 out. 2018.

VIEIRA, H. I. A.; FERREIRA, C. A. F. As aplicações móveis no ensino de história e no desenvolvimento da consciência história. Revista História Hoje. v. 5, n. 9, p. 205 - 220, 2016. Disponível em: https://rhhj.anpuh.org/RHHJ/article/view/244 Acesso em: 25 Out. 2018.

Recebido em julho de 2019.

Aprovado para publicação em maio de 2020.

Felipe Becker Nunes

Doutor em Informática na Educação - Universidade Federal do Rio Grande do Sul - UFRGS, Brasil, nunesfb@gmail.com

\section{Eleandro Viana da Rosa}

Mestre em Ensino de História - Universidade Federal do Rio Grande do Sul - UFRGS, Brasil, eleandroviana@gmail.com 